\title{
Synthesis of Amine Functionalized Mesoporous Silicas Templated by Castor Oil for Transesterification
}

Elianaso Elimbinzi ${ }^{1}$, Stephen S.Nyandoro*1 ${ }^{1}$, Egid B. Mubofu ${ }^{1}$, Amin Osatiashtiani ${ }^{2}$, Jinesh C. Manayil $^{2}$, Mark A. Isaacs ${ }^{2}$, Adam F. Lee ${ }^{3}$ and Karen Wilson $*^{3}$

${ }^{1}$ Chemistry Department, College of Natural and Applied Sciences, University of Dar es Salaam, Dar es Salaam, Tanzania

${ }^{2}$ European Bioenergy Research Institute (EBRI), Aston University, Aston Triangle, Birmingham, B4 7ET, $U K$

${ }^{3}$ School of Science, RMIT University, Melbourne VIC3000, Australia

*Corresponding authors:nyandoro@udsm.ac.tz; samyandoro@yahoo.com; karen.wilson2@rmit.edu.au

\section{ABSTRACT}

Mesoporous silicas were synthesized via a surfactant-templated sol-gel route using castor oil as the templating agent under acidic medium. The resulting silicas were subsequently amine functionalized with 3-aminopropyltriethoxysilane ( $\mathrm{NH}_{2}$-MTS), [3-(2-aminoethylamino)propyl]trimethoxysilane (NN-MTS), and [3-(diethylamino)propyl]trimethoxysilane(DN-MTS) to introduce surface basicity. Surface physicochemical properties were characterized by field emission gun scanning electron microscopy (FEGSEM), nitrogen porosimetry, $X$-ray photoelectron spectroscopy (XPS), thermogravimetric analysis (TGA), X-ray diffraction $(X R D)$, and diffuse reflectance infrared fourier transform spectroscopy (DRIFTS). Assynthesised materials exhibit type IV adsorption-desorption isotherms characteristic of mesoporous structures. Clusters of spherical shaped materials were observed by FEGSEM, suggesting growth of silica occurs within colloidal dispersions. High-resolution $N$ is XP spectra and DRIFT spectra confirmed the presence of amine groups in the organo-amine functionalised mesoporous silicas. The amine functionalised mesoporous silicas were active for the transesterification of tributyrin with methanol, with conversion found to increase from $\mathrm{NH}_{2}-\mathrm{MTS}<\mathrm{NN}-\mathrm{MTS}<\mathrm{DN}-\mathrm{MTS}$. 


\section{INTRODUCTION}

Castor oil is a non-edible naturally occurring triglyceride composed of glycerol and free fatty acid chains with approximately ninety percent of the fatty acid chains being ricinoleic acid[1,2]. Castor oil has unique properties owing to the presence of a hydroxyl group in addition to carboxylic and olefinic groups in ricinoleic acid, which makes the oil a good candidate for transformation by different chemical reactions such as hydrogenation, epoxidation, saponification, esterification, pyrolysis, sulphonation and polymerizations [3]. Thus, various chemicals such as sebacic acid, undecylenic acid, 2octanol can be obtained from the castor oil[4]. Castor oil and ricinoleic acid have also been reported as a capping agent for nanoparticles synthesis[5,6] and have been used for biodiesel production via esterification and transesterification, respectively[7,8].

Synthesis of mesoporous silica materials have attracted attention due to their properties which support a variety of applications[9-11]. Mesoporous solid supports are typically synthesized via non-renewable petroleum-derived polyol or alkylamine surfactant templates such as pluronic P123, cetyltrimethylammonium bromide and dodecylamine[12-14]. However, these artificial surfactants are expensive, harmful to the environment, toxic and not easily available. The search for renewable surfactants that are naturally available and environmentally friendly in synthesizing mesoporous materials is necessary. Thus, the use of natural and renewable surfactant including castor oil for the synthesis of mesoporous materials are gaining importance[15-18]. Castor oil is suitable to be used as pore directing agent during the synthesis of mesoporous materials due to the carboxylic acid and hydroxyl groups of the ricinoleic acid. This makes the oil an amphiphilic molecule as it contains polar head and nonpolar tail[18]. Consequently, in the present work, the occurrence of hydrophilic head and hydrophobic tail in castor oil was envisaged to facilitate micelles formation when mixed with water/ethanol/ $\mathrm{HCl}$, hence making the castor oil the structural directing agent. Functionalization of the mesoporous material can be performed via a one pot-synthesis[11,14,18] or postsynthesis approach[19,20]. Thus, in this report, castor oil which is biodegradable and renewable material was used as a natural surfactant for the synthesis of the mesoporous materials. The synthesized mesoporous materials were functionalized using primary, secondary and tertiary amine to introduce surface basicity, with the impact on catalyst activity for the transesterification of $\mathrm{C}_{4}$ triglyceride, a model reactant for evaluating catalysts for biodiesel synthesis explored.

\section{EXPERIMENTAL}

\section{Materials and Chemicals}

Castor seeds were collected from Iringa and Dodoma regions of Tanzania. Tetraethyl-orthosilicate (TEOS), hydrochloric acid, ethanol, $n$-hexane, potassium hydroxide, potassium bromide, 3-aminopropyltriethoxysilane $\left(\mathrm{RNH}_{2}\right)$, 2,3aminoethylamino)propyltrimethoxysilane $(\mathrm{NN})$, 3-diethylaminopropyltrimethoxysilane (DN), dry toluene, methanol, tributyrin (TB), methyl butyrate (MB), dihexylether (DHE) were bought from Sigma Aldrich and used without further purification. 


\section{Castor oil extraction}

Castor oil was obtained by Soxhlet extraction using $250 \mathrm{~mL} n$-hexane as the extracting solvent. $10 \mathrm{~g}$ of crushed castor seeds were placed in a thimble in the centre of the extractor and $n$-hexane heated in a round bottom flask at $60{ }^{\circ} \mathrm{C}$, and the $\mathrm{n}$-hexane vapor condensed and passed through the thimble. The extract was collected in the round bottom flask for $6 \mathrm{~h}$, with $2 \mathrm{~mL}$ of castor oil obtained per $10 \mathrm{~g}$ of crushed castor seeds.

\section{Synthesis of mesoporous templated silica (MTS) using castor oil}

$2.5 \mathrm{~g}$ castor oil was dissolved in a stirred mixture of $53 \mathrm{~mL}$ distilled water, 47 $\mathrm{mL}$ ethanol, and $10 \mathrm{~mL} 2 \mathrm{M} \mathrm{HCl}$. The mixture was stirred at $35^{\circ} \mathrm{C}$ for $2 \mathrm{~h}$ prior to the addition of $23 \mathrm{~mL}$ TEOS and then stirred for a further $24 \mathrm{~h}$, prior to aging at $80{ }^{\circ} \mathrm{C}$ for an additional $24 \mathrm{~h}$ in a sealed vessel. The organic template was subsequently removed by Soxhlet extraction using $200 \mathrm{ml}$ of ethanol as the extracting solvent during reflux at 70 ${ }^{\circ} \mathrm{C}$ for $10 \mathrm{~h}$. The parent mesoporous templated silica (MTS) was obtained by filtration and ambient drying.

\section{$\underline{\text { Functionalization of MTS }}$}

$2 \mathrm{~g}$ MTS was oven dried at $100^{\circ} \mathrm{C}$ for $1 \mathrm{~h}$, and then dispersed in dry toluene under stirring for $1 \mathrm{~h}$, followed by addition of $\mathrm{RNH}_{2}, \mathrm{NN}$, or DN as represented in Figure 1.Each of the resulting mixtures was subsequently refluxed at $130{ }^{\circ} \mathrm{C}$ for $24 . \mathrm{In}$ all cases, solid powders were obtained by filtration, methanol washing and dried overnight at 100 ${ }^{\circ} \mathrm{C}$. The resulting functionalized mesoporous materials were termed $\mathrm{NH}_{2}-\mathrm{MTS}, \mathrm{NN}-$ MTS, and DN-MTS.
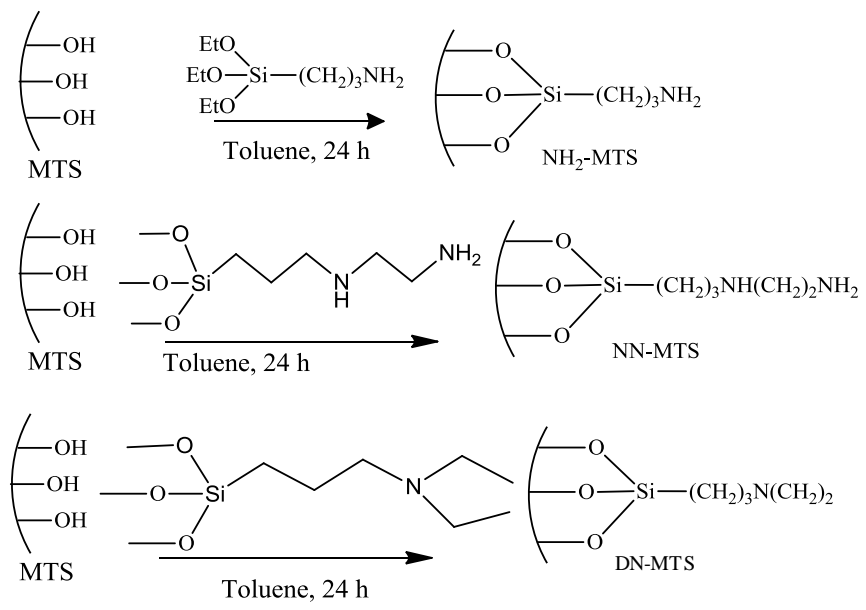

Figure 1. Reaction scheme showing amine grafted to the MTS

\section{$\underline{\text { Transesterification reactions }}$}

Transesterification reactions were performed at $60{ }^{\circ} \mathrm{C}$ using a Radleys reactor station employing $10 \mathrm{mmol}$ of Tributyrin (TB) (C4), $1 \mathrm{mmol}$ of dihexylether, DHE (internal standard), $300 \mathrm{mmol}$ of methanol and $50 \mathrm{mg}$ of catalyst in a two-necked round 
bottomed flask. Reactions were run for $24 \mathrm{~h}$ with samples collected periodically and filtered and diluted in dichloromethane prior to analysis by gas chromatography. $\mathrm{C} 4$ conversion was monitored using a Varian 450-GC equipped with a Phenomenex ZB-5HT Inferno $15 \mathrm{~m} \times 0.32 \mathrm{~mm} \times 0.10 \mu \mathrm{m}$. All catalytic profiles are an average of 3 injections per sample.

\section{MTS characterization}

Powder X-ray diffraction patterns were measured on a Bruker AXS D8 Advance X-Ray diffractometer, equipped with nickel filtered $\mathrm{Cu} \mathrm{K}_{\alpha}$ radiation $(\lambda=1.5406$ $\AA$ ). Nitrogen physisorption was performed using a Quantachrome Nova 4200 porosimeter. Pore size distributions were determined using the Barrett-Joyner-Halend (BJH) method, applied to the desorption branch of the isotherms, while surface areas were determined by the Brunauer- Emmett-Teller (BET) method for $p / p_{0}$ between 0.05 $0.3[21,22]$. Samples were degassed at $120{ }^{\circ} \mathrm{C}$ for $3 \mathrm{~h}$ prior to analysis. Morphology was determined using a Zeiss Ultra Plus Field Emission Gun Scanning Electron Microscopy (FEG SEM) was used for the surface morphology analysis at $10 \mathrm{kV}$. Samples were carbon coated using Quorum coater (Model Q150TE) prior to SEM characterization. DRIFTS measurements were conducted in air using a Thermo Nicolet 6700 FTIR spectrometer on samples diluted $10 \mathrm{wt} \%$ in dry $\mathrm{KBr}$ were used to perform a background subtraction and obtain the adsorbate bands. Surface compositions were determined by XPS using a Kratos Axis HSi spectrometer equipped with a charge neutralizer and monochromated $\mathrm{Al} \mathrm{K}_{\alpha}$ source $(1486.7 \mathrm{eV})$ at normal emission; binding energies were referenced to adventitious carbon at $284.8 \mathrm{eV}$. TGA was performed using PerkinElmer Pyris 6 thermal analyzer under flowing $\mathrm{N}_{2}\left(30 \mathrm{ml} / \mathrm{min}\right.$ ) between $40-800{ }^{\circ} \mathrm{C}$ (ramp rate 10 $\left.{ }^{\circ} \mathrm{C} / \mathrm{min}\right)$.

\section{RESULTS AND DISCUSSION}

The textural properties of the synthesized MTS and functionalized MTS were studied by $\mathrm{N}_{2}$ porosimetry at $77 \mathrm{~K}$. Figure 2 shows the $\mathrm{N}_{2}$ adsorption-desorption isotherms and BJH pore size distribution of the parent MTS and amine functionalized MTS. All synthesized materials exhibited type IV adsorption-desorption isotherms with a hysteresis loop in the partial pressure range from $0.55-0.8$ which are characteristic features of mesoporous materials associated with capillary condensation taking place in mesopores[23]. The amount of adsorbed nitrogen decreased upon grafting different organoamine groups due to partial blockage of pores upon surface modification, resulting in decreased surface area, pore diameter and pore volume (Table I). In addition, this decrease could be partly attributed to oligomerisation of the amino-silanes to form oligosiloxanes which partially block pores. The surface area of the parent MTS decreased from $899 \mathrm{~m}^{2} / \mathrm{g}$ to 510,407 and $246 \mathrm{~m}^{2} / \mathrm{g}$ upon modification with $\mathrm{RNH}_{2}, \mathrm{NN}$, and $\mathrm{DN}$, respectively indicating more significant blockage as the bulkiness of the organoamines increased. While the porosimetry shows materials to be mesoporous, no low angle peak was observed by XRD, indicating that there was no long range order of the pores. 

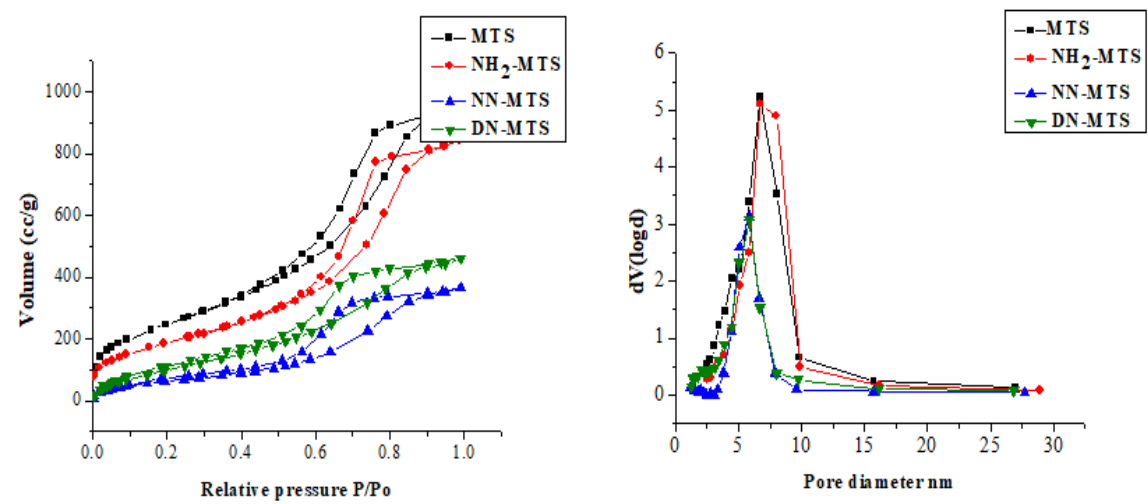

Figure 2. $\mathrm{N}_{2}$ isotherms and pore size distribution for MTS and amines functionalized MTS.

Table I. Textural properties of non-functionalized and functionalized MTS.

\begin{tabular}{llll}
\hline Sample & $\begin{array}{l}\text { BET surface } \\
\text { area }\left(\mathrm{m}^{2} / \mathrm{g}\right)\end{array}$ & $\begin{array}{l}\text { Total pore } \\
\text { volume }(\mathrm{cc} / \mathrm{g})\end{array}$ & $\begin{array}{l}\text { BJH Pore diameter } \\
(\mathrm{nm})\end{array}$ \\
\hline MTS & 899 & 1.47 & 6.7 \\
$\mathrm{NH}_{2}$ MTS & 510 & 1.32 & 6.1 \\
NN-MTS & 407 & 0.63 & 5.8 \\
DN-MTS & 246 & 0.84 & 5.4 \\
\hline
\end{tabular}

TG analysis and DTG curves of the synthesized materials are presented in Figure 3.Synthesized MTS, amine functionalized MTS had weight loss below $100{ }^{\circ} \mathrm{C}$ associated with physisorbed water, followed by large weight loss for functionalized materials at $300-500{ }^{\circ} \mathrm{C}$ attributable to the decomposition of aminopropyl functional groups. Furthermore, heating $>600{ }^{\circ} \mathrm{C}$ led to additional weight loss ascribed to condensation of silanol group condensation.

The surface morphology analyzed by SEM indicated clusters of spherical structures for all functionalized MTS as represented in Figure 4.
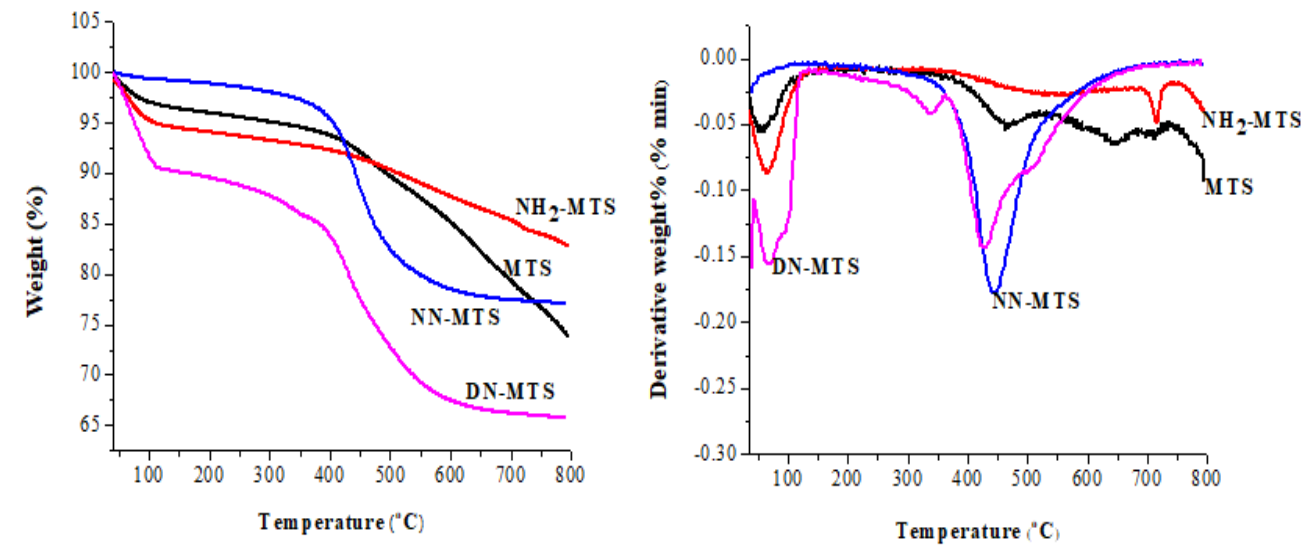

Figure 3.TGA and DTG curves of parent MTS and amine functionalized MTS. 


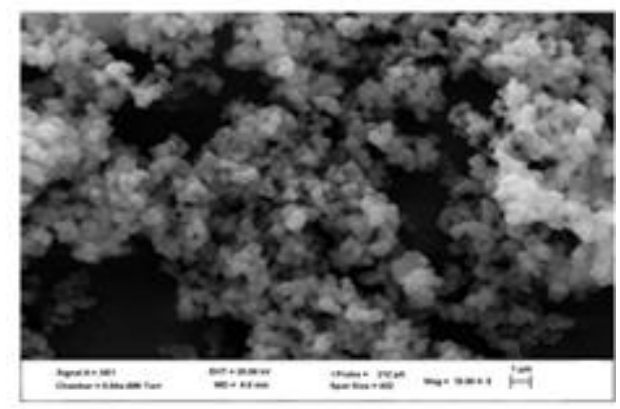

Figure 4. SEM micrograph of $\mathrm{NH}_{2}-\mathrm{MTS}$.

Surface analysis of the chemical composition on the silica grafted groups was analyzed by XPS which revealed all samples exhibited an N 1s peak centred 398.8 eV characteristic of amine groups evidencing the successful attachment of $\mathrm{N}$ containing groups. The resulting surface compositions are shown in Table II which shows the surface $\mathrm{N}$ content of $\mathrm{NH}_{2}$-MTS and DN-MTS are comparable, while that of NN-MTS is higher, consistent with the compositions of the organo-amines. This also suggests that the surface loading of grafted organic groups is comparable for three organosilanes explored.

Table II: Surface elemental composition of organo-amine functionalized MTS samples

\begin{tabular}{llllll}
\hline Sample & $\begin{array}{l}\text { Atomic } \\
\text { Si }(\%)\end{array}$ & $\begin{array}{l}\text { Atomic } \\
\mathrm{C}(\%)\end{array}$ & $\begin{array}{l}\text { Atomic } \\
\mathrm{O}(\%)\end{array}$ & $\begin{array}{l}\text { Atomic } \\
\mathrm{N}(\%)\end{array}$ & $\begin{array}{l}\text { mmol } \\
\text { N/g cat }\end{array}$ \\
& & & & & \\
NH$_{2}$-MTS & 17.5 & 32.0 & 47.4 & 3.2 & 1.65 \\
NN-MTS & 10.9 & 48.8 & 36.7 & 3.7 & 2.39 \\
DN-MTS & 14.6 & 38.6 & 44.0 & 2.8 & 1.76 \\
MTS & 10.7 & 54.1 & 35.2 & - & - \\
\hline
\end{tabular}

Confirmation of the nature of the grafted groups was provided DRIFT Figure 5 which shows the IR spectra of the non-functionalized and functionalized MTS. All samples show strong bands for Si-O-Si at $1067 \mathrm{~cm}^{-1}$ for the support, with the parent MTS, also exhibiting peaks at 3569 and $970 \mathrm{~cm}^{-1}$ due to the presence of $\mathrm{Si}-\mathrm{OH}$. Following functionalization with organo-amine groups, the $\mathrm{Si}-\mathrm{OH}$ features are attenuated and a C-N stretching mode was observed $\sim 1250 \mathrm{~cm}^{-1}$. A new band emerges around 3250$3400 \mathrm{~cm}^{-1}$ for $\left(\mathrm{NH}_{2}\right.$-MTS) and (NN-MTS) characteristic of primary $\mathrm{NH}_{2}$ vibrations. For tertiary amines (DN-MTS), there was no N-H band observed in this region. $\mathrm{C}-\mathrm{H}$ stretching band at range $2850-3000 \mathrm{~cm}^{-1}$ was observed for all amine functionalized MTS. 


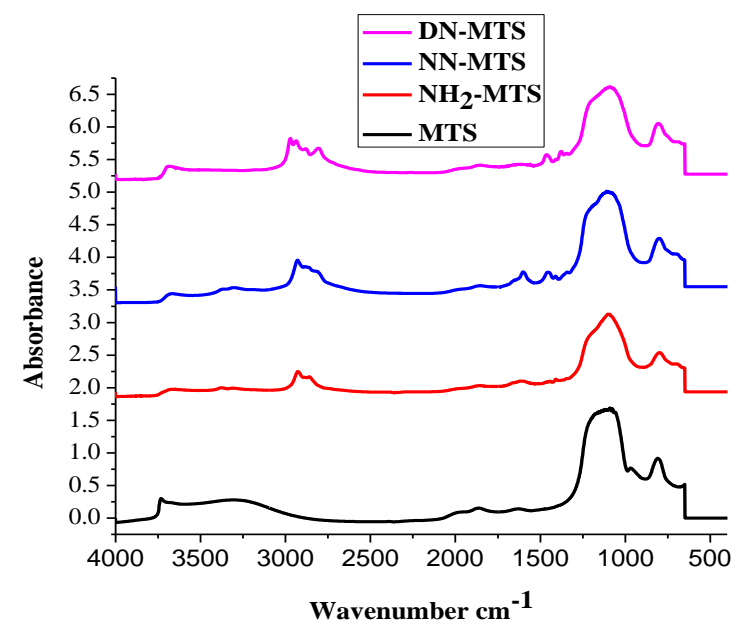

Figure 5. DRIFT spectra for MTS functionalized with organo-amines.

\section{Catalytic activity}

The catalyst activity was investigated by transesterification of tributyrin at 60 ${ }^{\circ} \mathrm{C}$ (Figure 6). Conversion and yield were observed to increase from $\mathrm{NH}_{2}$-MTS $(8.9 \%$, $2.8 \mathrm{mmol})<\mathrm{NN}-\mathrm{MTS}(22 \%, 3.9 \mathrm{mmol})<\mathrm{DN}$-MTS $(26.7 \%, 4.3 \mathrm{mmol})$ suggesting there is an impact of amine functionality on transesterification activity. The initial rates for conversion of TB were $0.076,0.173$ and $0.593 \mathrm{mmolh}^{-1}$ respectively, which when normalized by the $\mathrm{N}$ content per g catalyst used (Table II) gives turnover frequencies of $0.9,6.75$ and $1.45 \mathrm{~h}^{-1}$ for $\mathrm{NH}_{2}$-MTS, NN-MTS and DN-MTS catalysts respectively, confirming the superior performance of the tertiary amine.
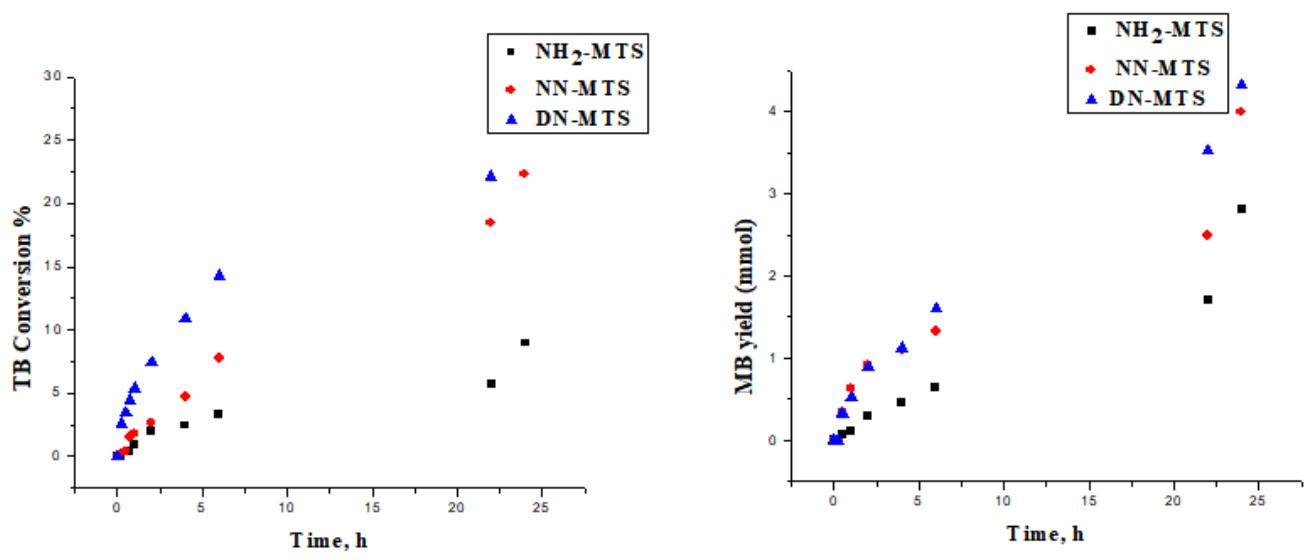

Figure 6. (Left) tributyrin conversion and (Right) methylbutyrin yield, during transesterification of tributyrin with methanol using amine functionalized MTS catalysts. 
Future work will explore the quantitative relationships between base site loading and strength and activity, and benchmark these against the established literature for alternative solid acid catalysts[24-26], notably sulfonic acid functionalised mesoporous silica analogues[27-29].

\section{CONCLUSIONS}

Mesoporous silicas were successfully synthesized using castor oil as poredirecting agent under acidic conditions. The obtained mesoporous silicas were suitable for functionalization using organoamines via post-synthesis method to produce solid base catalysts, with the effect of primary, secondary and tertiary amines explored. The synthesized materials showed large surface area and uniform pore size distribution which is a desired characteristic of mesoporous materials, in spite of lack of long range order of the pores. Surface loadings of organoamine groups were comparable suggesting the grafting efficiency of $\mathrm{RNH}_{2}, \mathrm{NN}$ and DN organosilanes were similar and not restricted by changes in steric bulk. Transesterification reactions using the basic modified MTS surface was achieved and demonstrated an increase in conversion of TB as the catalyst was varied from $\mathrm{NH}_{2}$-MTS to DN-MTS suggesting the tertiary amine is more efficient for transesterification and has potential for biodiesel synthesis.

\section{ACKNOWLEDGMENT}

Financial support by Leverhulme Royal Society African Award and Mkwawa University College of Education (MUCE) is gratefully acknowledged.

\section{REFERENCES}

1. A. Omari, Q. A. Mgani, and E. B. Mubofu, Green Sustain. Chem.5, 154-163 (2015).

2. B. S. Shridhar, K. V Beena, M. V Anita, and K. B. Paramjeet, LJS. 17, 59-70 (2010).

3. $\quad$ E. B. Mubofu, Sustain. Chem. Process. 4(1), 11-23(2016).

4. $\quad$ N. Azcan and E. Demirel, Ind. Eng. Chem.Res.47, 1774-1778(2008).

5. J. W. Kyobe, E. B. Mubofu, and Y. M. M. Makame, New J. Chem.39, 7251-7259 (2015).

6. J. William, E. Beatus, Y. M. M. Makame, and S. Mlowe, Phys. E Low-dimensional Syst. Nanostructures.76, 95-102 (2016).

7. $\quad$ G. Wang and S. Sun, J. Oleo Sci.66 (7), 753-759 (2017).

8. S. Ismail, A. S. Ahmed, R. Anr, and S. Hamdan, J. Renew. Energy. 2016, 1-8(2016).

9. M. Hasanzadeh, N. Shadjou, M. de la Guardia, M. Eskandani, and P. Sheikhzadeh, TrAC-Trends Anal. Chem.33, 117-129(2012).

10. C. Bharti, N. Gulati, U. Nagaich, and A. Pal, Int. J. Pharm. Investig.5 (3), 124-133, (2015).

11. A. V Biradar, V. S. Patil, P. Chandra, D. S. Doke, and T. Asefa, Chem. Commun.51, (40), 8496-8499 (2015).

12. A. Sundblom, A. E. C. Palmqvist, and K. Holmberg, Langmuir, 26 (3), 1983-1990(2010).

13. $\quad$ E. Bad’urová, K. Raabová, and R. Bulánek, Dalt. Trans.43 (10), 3897-3905 (2014).

14. L. Yang, Y. Guo, W. Zhan, Y. Guo, Y. Wang, and G. Lu, Microporous Mesoporous Mater.197, 1-7(2014).

15. F. B. Hamad, E. B. Mubofu, and Y. M. M. Makame, Catal. Sci. Technol.1 (3), 444452(2011).

16. E. B. Mubofu, J. E. G. Mdoe, and G. Kinunda, Catal. Sci. Technol.1 (8), 14231431(2011).

17. S. C. Msigala and Mdoe J. E. G, Tanzania J. Sci. vol. 38(1), 24-34 (2012).

18. M. Andrew and E. B. Mubofu, Int. Res. J. Pure Appl. Chem.15 (1), 1-12(2017).

19. N. I. Taib, S. Endud, and M. N. Katun, Int. J. Chem.3(3), 2-10(2011).

M. Mu, X. Yan, Y. Li, and L. Chen, J. Nanoparticle Res. 19(4),148-161(2017).

G. Fagerlund, Mater. Constr.6 (3), 239-245 (1973). 
24. A.F. Lee, J.A. Bennett, J.C. Manayil and K. Wilson, Chem. Soc. Rev. 43, 7887-7916 (2014)

25. K. Wilson and A.F. Lee, Catal. Sci. Technol. 2, 884-897 (2012).

26. K. Wilson and A.F. Lee, Phil. Trans. R. Soc. A 374, 20150081 (2016).

27. C. Pirez, J.-M. Caderon, J.-P. Dacquin, A.F. Lee and K. Wilson, ACS Catal. 2, 1607$1614(2012)$.

28. J.-P. Dacquin, C. Pirez, A.F. Lee and K. Wilson, Chem. Comm. 48, 212-214 (2012).

29. C. Pirez, A.F. Lee, J.C. Manayil, C.M.A. Parlett and K. Wilson, Green Chem. 16, 45064509 (2014). 